\title{
Low Testosterone-An Important Predictor of Low Mineral Bone Density in Young Men-Our Own Experience and a Review of Literature
}

\author{
Michael Funaro, Alexander Bolyakov, Elena Gimenez, Michael Herman, Darius A. Paduch* \\ Department of Urology and Reproductive Medicine, Weill Cornell Medical College, New York, USA \\ Email: *dap2013@med.cornell.edu
}

Received June 1, 2013; revised July 1, 2013; accepted July 10, 2013

Copyright (C) 2013 Michael Funaro et al. This is an open access article distributed under the Creative Commons Attribution License, which permits unrestricted use, distribution, and reproduction in any medium, provided the original work is properly cited.

\begin{abstract}
Urologists and reproductive endocrinologists have become the first contact physicians for young men of reproductive age and have the unique opportunity to positively affect men's health and quality of life. Growing evidence indicates that a significant proportion of men presenting with infertility or sexual dysfunction are hypogonadal. One hundred ninety nine men were enrolled in our center, and mean total testosterone was $<300 \mathrm{ng} / \mathrm{dl}$. Patients were divided into three groups based on their DEXA scan results; normal bone density $(n=122,57 \%)$, osteopenia $(n=69,39 \%)$ and osteoporosis $(\mathrm{n}=8,4 \%)$. There were no differences in the mean age $(\mathrm{p}<0.64)$, height $(\mathrm{p}<0.99)$ and weight $(\mathrm{p}<0.06)$ among the three groups (ANOVA), but men with osteopenia had statistically significant lower weights $(\mathrm{p}<0.02)$. Our results indicate that hypogonadism is one of the main risk factors for osteopenia and osteoporosis which can be found in $8 \%$ of hypogonadal men younger than 50 years of age. Testosterone replacement therapy may be indicated in most men with hypogonadism and low bone mineral density (BMD); however the benefits of testosterone treatment in eugonadal men are unproven. Selective estradiol and androgen receptor modulators expand our treatment modalities in men of reproductive age when suppression of gonadotropins may interfere with reproductive plans. Early detection of hypogonadism and osteoporosis may lower the risk of hip and vertebral fractures in some men. Further prospective RCTs are needed to prove cost-effectiveness of detection and the best treatment of osteoporosis in hypogonadal men of reproductive age. Urologists have the opportunity to be at the forefront of greater awareness of this clinical problem due to their frequent contact with this population of patients.
\end{abstract}

Keywords: Osteopenia; Osteoporosis; Hypogonadism; Infertility; Sexual Dysfunction

\section{Introduction}

Osteopenia, osteoporosis, hip fractures and their complications have significant morbidity and mortality in women and men of advanced age $(>70)[1,2]$. Osteoporosis is often viewed by medical professionals and laymen alike as a disease of the elderly, and not considered in the differential of clinical problems of middle-aged or young men. Furthermore, growing epidemiological evidence suggests that low bone mineral density may be more common in younger men (20 - 40's) than previously believed [3].

The clinical and socioeconomic impact of osteoporosis in older men is significant; one third of hip fractures occur in male patients and hip fracture related mortality is higher among older men than women [4]. Vertebral frac-

*Corresponding author. tures secondary to osteoporosis may not necessitate surgical treatment, but they contribute to decreased height, back pain, decreased functional lung capacity, and increased risk of death. Despite increased mortality and decreased quality of life as a direct effect of osteoporosis in older men, it often remains an undiagnosed problem due to the lack of clinical suspicion and mistaken clinical biases. The existing literature focuses almost exclusively on older men (more than 65 years old), and these men are often already presenting with complications of low BMD such as hip fractures [5]. Little attention is paid to addressing low BMD before these complications occur. It has been clearly established that low testosterone together with chronic glucocorticoid or corticosteroid use are the leading causes of osteoporosis in men. Hypogonadism was diagnosed in up to $66 \%$ of elderly men with hip fractures, with most patients being asymptomatic 
[6]. There has been little clinical interest in addressing similar complications in symptomatic hypogonadal men of reproductive age at risk for low BMD and potentially preventing these complications.

Androgen deprivation therapy (ADT) is commonly used to manage advanced prostate cancer. Experience with these patients demonstrated clearly that lowering serum testosterone levels accelerates age-related annual decreases in bone density and significantly increases the risk of osteoporosis [7]. Screening for preexisting osteoporosis in men with advanced prostate cancer allows for early detection of men at risk of vertebral and hip fractures and early institution of preventative measures [8]. Lessons learned from this subset of patients should also be applied to young, hypogonadal men. In current urological practice, these men often present for care dealing with infertility or sexual dysfunction, and as such urologists are presented with an opportunity to address this often overlooked aspect of their care. Management of sexual dysfunction, infertility, and low testosterone is an integral part of urological training and practice. Urologists are in a unique position to identify men with hypogonadism early in life and assess their risk of hypogonadism and low bone mineral density-potentially monitoring and intervening before costly and morbid late life complications occur.

This review focuses on the current pathophysiology, diagnosis, and management of low bone mineral density (BMD) and how knowledge of these topics may be applied to the younger male patient who often presents to urological care for other matters such as infertility or sexual dysfunction.

1) Epidemiology of osteopenia and osteoporosis.

It is estimated that in the group of men older than 50, the prevalence of osteoporosis is approximately 5\% [9]. The distribution of osteoporosis differs between races, with lowest prevalence is among Hispanics (3\%) and highest among white men (7\%) [10-12]. Men typically develop osteoporotic fractures 10 years later than females. After the age of 75, the incidence of fractures increases rapidly. As the population ages, the prevalence of osteoporosis-related fractures is expected to increase dramatically [10]. Once a hip fracture occurs in men, the morbidity and mortality related to low bone mass are much higher than expected for women. Short term (in-hospital) and long term (one year) hip fracture related mortality are twice as high in men as is in women when correcting for socioeconomic status and age. Thus the prevention of hip fractures and osteoporosis has a direct impact on reducing morbidity and mortality among men, and a magnified economic impact as well when compared to female counterparts [13]. This becomes a significant issue for medical economics and quality of life, as more than half of men with hip fractures suffer from chronic pain and require assistance walking six months after surgery. One third of these men have to be placed in long-term care facilities, which is known to negatively affect men's self esteem, independence and overall quality of life [14].

2) Bone physiology.

Bone provides the frame and strength necessary for mobility and protection, in addition to its role as a major reservoir for calcium, phosphorus, magnesium and other ions. Cortical bone forms the outer hard layer, and trabecular (cancellous) bone fills the inner space, structurally supporting bone marrow. Bone undergoes constant remodelling by two types of cells: osteoblasts and osteoclasts. Osteoblasts form new bone matrix and osteoclasts are responsible for resorption of the bone (Figure 1). Bone has three different components: cellular, extracellular, and mineral. Osteoblasts, osteoclasts, osteocytes, blood vessels and lymphatics constitute the cellular components of bone. The extracellular compartment consists mainly of type I collagen and organic matrix. Type I collagen is suspended in matrix which has multiple different proteins such as albumin, osteopontin, fibronectin and collagen binding proteins. Those proteins are responsible for cell to cell interaction and signaling. Calcium and phosphorus are necessary for bone mineralization. Crystalline hydroxyapatite is deposited in the holes created between collagen fibrils and hydroxyapatite and is responsible for bone strength [15]. The adequate balance between cellular and mineral components in the bone is a prerequisite for functional mechanical integrity of and

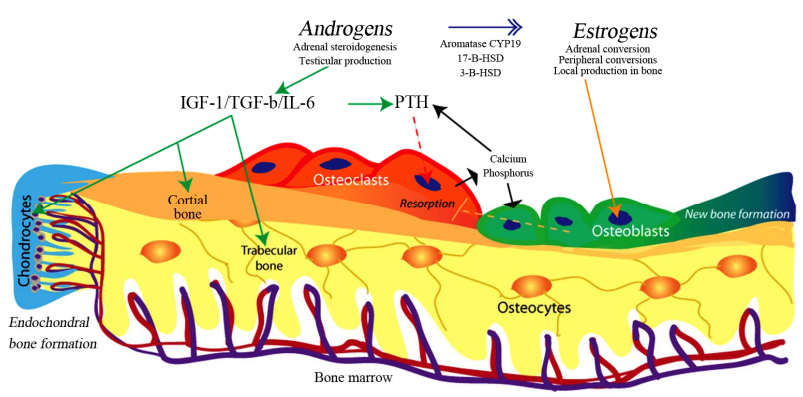

Figure 1. Bone structure, cellular elements, and major pathways of hormonal control in men. Osteoclasts start resorption of bone through signaling initiated by osteocytes (microfractures), or low calcium levels. This process is under PTH (positive) and estradiol (negative) control, through direct action of PTH and Estrogen on osteoblasts. With initiation of bone resorption, the opposite process of bone formation is carried out by osteoblasts. Androgens stimulate chondrocytes proliferation and periostal bone formation stimulating long bone growth. Estradiol closes epiphyses. Androgens produced in testis and adrenals are converted to estradiol through peripheral and local action of aromatase CYP19 and other enzymes. This diagram is simplified and doesn't include cell-cell signaling, and role of novel proteins like metalloproteases among others. Please see text for full explanation of interactions. 
metabolic function of bone. Normal bone undergoes constant remodeling necessary for growth and repair of daily impact microfractures (daily wear and tear) [16].

Osteoblasts are found in the areas of new bone formation and are derived from mesenchymal cells. Osteoblasts produce and release organic matrix. Full bone mineralization can take up to 3 - 5 months and it is regulated by inhibitors of mineralization which undergo hydrolysis by alkaline phosphatase. Since alkaline phosphatase is released by osteoblasts and released into ECS, it can be used to assess function of osteoblasts [17]. Mineralization of the bone changes the environment around osteoblasts and stimulates their transformation into osteocytes. Osteocytes serve as sensors of any damage or changes to normal bone structure. Any damage to the bone or decreased mineralization is then signaled to osteoclasts and then to osteoblasts to initiate bone remodeling [18].

Resorption of the bone is carried out by osteoclasts, multi-nucleated cells which are of bone marrow origin. Osteoblasts control normal development of osteoclasts via macrophage colony stimulating factor and an array of cytokines. Both parathyroid hormone $(\mathrm{PTH})$ and vitamin $\mathrm{D}\left(1.25(\mathrm{OH})_{2} \mathrm{D}\right)$ increase osteoclast number and activity. Osteoclasts lack the PTH receptor and require osteoblasts to release RANKL, which binds to RANK receptor in osteoclasts and stimulates their proliferation [19]. Estrogen decreases osteoclast number and activity through an indirect mechanism and thus prevents bone loss [20]. Resorption of mineralized bone is initiated by osteoclasts, which release the proton's chloride into the extracellular space. The proton pump ATPase lowers the $\mathrm{pH}$ and bone matrix loses its calcium; subsequently the organic matrix is digested through proteinases such as cathepsin $\mathrm{K}$.

Normal bone structure and mineralization depends on the adequate balance between osteoblasts and osteoclasts. During puberty bone formation exceeds bone resorption and in early twenties men achieve their peak BMD. With aging, the process of bone formation and resorption achieves homeostatic equilibrium and during adulthood the same amount of bone is formed and destroyed per unit of time. The activity of osteoblasts and osteoclasts can be measured using bone alkaline phosphatase and osteocalcin levels; both are released by osteoblasts and detected by measurement of serum and urine levels of cross link peptides which are formed at the time of resorption of cross-linked collagen fibers in the bone.

Serum calcium levels are closely regulated by parathyroid hormone and vitamin $\mathrm{D}\left(1.25(\mathrm{OH})_{2} \mathrm{D}\right)$. Vitamin D suppresses release of PTH, similar to the effect (on PTH) of elevated serum calcium levels. Orally ingested calcium is absorbed in the proximal small intestine where low $\mathrm{pH}$ aids in adequate absorption. Passive absorption has relatively low role in daily calcium absorption and majority of calcium is absorbed under control of vitamin D. Large doses of calcium carbonate are a much less efficient way of calcium supplementation because of alkalizing properties of calcium carbonate. In patients on proton pump inhibitors, calcium citrate is a better option for calcium supplementation since it lowers intraintestinal $\mathrm{pH}$. In the United States an average adult will digest from $0.5 \mathrm{~g}$ to $1.5 \mathrm{~g}$ of calcium a day; however, only 200 $\mathrm{mg}$ to $400 \mathrm{mg}$ is absorbed daily. At the same time 8 to 10 $\mathrm{g}$ of calcium are released from bone and pass through the kidneys [21]. The kidneys have a very tight mechanism of controlling of calcium secretion since the kidneys serve as a major regulator of calcium levels. Most of the calcium is absorbed through the passive mechanism in the proximal tubules and re-absorption in the distal tubules is regulated through the PTH and vitamin D. Despite this regulation, the intestines and skin have an inexorable daily calcium loss estimated to be approximately $200 \mathrm{mg}$ per day. Thus patients with low calcium intake cannot provide enough calcium to overcome obligatory losses despite normally functioning control of the calcium metabolism.

Both men and women achieve peak bone mineral density (BMD) in their early twenties [22]. The peak BMD depends on genetic background (family history), caloric and calcium intake, normal hormonal levels during childhood and adolescence [23]. Therefore, problems affecting general health and nutrition during childhood will result in lower peak BMD (Figure 2). For example, a 20-year-old man with severe hypogonadism as a result of Kallmann syndrome will achieve lower peak BMD than his peers. Assuming similar rates of annual decline

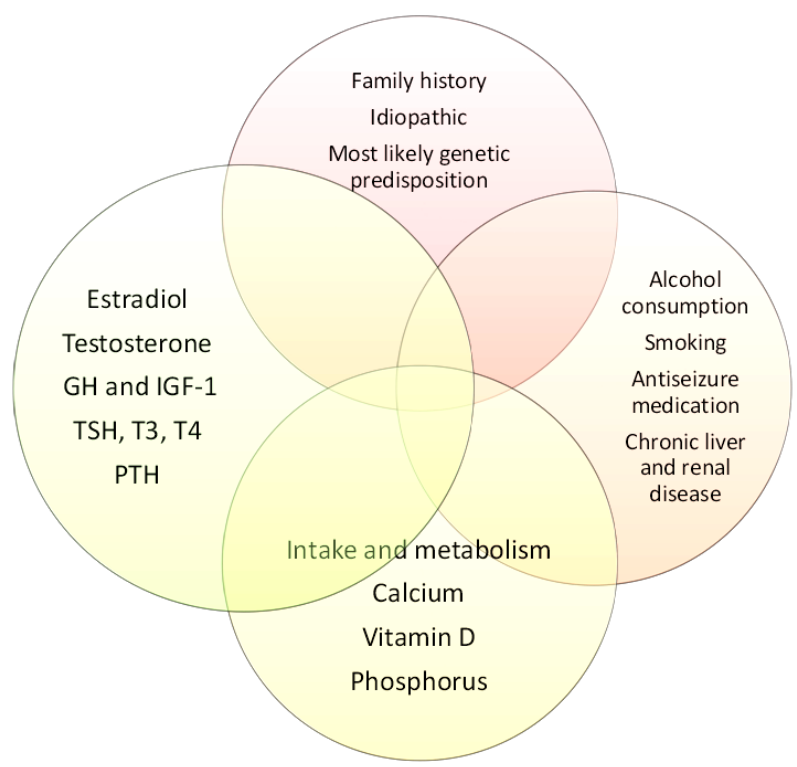

Figure 2. Normal bone density depends on close interactions between genetic, environmental, hormonal, and dietary factors. 
$(1 \%-3 \%)$ in BMD, men with lower peak BMD to begin with are at much higher risk of developing early osteoporosis. Although physiological loss of BMD begins around age of 50, any men with lower testosterone will suffer from accelerated annual BMD loss, since normal hormonal status is necessary to sustain normal mineralization.

3) Bone mineral density and the role of sex steroids.

Epidemiological data showing increased risk of hip fractures and osteoporosis in postmenopausal females and orchiectomized men established that sex steroid hormones (estrogens and androgens) are necessary for normal bone structure and mineralization in both men and women [24-26]. However, the molecular mechanism that conveys the action of testosterone and estradiol necessary for normal BMD in men and women as well as in different age groups is still debated and an area of intensive clinical and basic science research [27-29].

Estradiol suppresses resorption of bone carried out by osteoclasts thus indicating importance of estrogens in bone metabolism. In humans and most of animals regardless of sex, estrogens are derived from androgens through the action of aromatase CYP19 (Figure 1) [30,31]. Thus, defects in steroidogenesis, inadequate aromatization or inactivation mutations in theEndoplasmic Reticulum will result in decrease in estradiol dependent gene expression [32]. This principal action of estradiol on bone metabolism is evident in men and mice with an inactivating mutation in the estrogen receptor or aromatase CYP19, who develop early onset osteoporosis [33]. Those observations strongly support the need for normal testosterone levels and adequate conversion of testosterone to estradiol to sustain normal BMD. It is important to note however that men with CYP19 deficiency show no effect on the axial growth of long bones, indicating that androgens specifically play a role in long bone growth [34].

At a biomechanical level, the differences in bone structure between men and women can be explained by differences in apposition of the bone [34]. In men, the periosteal deposition predominates, whereas in females the endocortical apposition predominates (Figure 1) [35]. Differences in length are directly related to timing of epiphyseal closure-an estradiol dependent event. In men the bones are longer because peak estradiol levels occur later than in women. After puberty, the sex-related bone dimorphism depends on the larger mass of the bone (especially in the bone cortex) in men as compared to women. Men have the greater total bone volume but volumetric density in men and bone mineral density (expressed per units of volume) are similar in men and women. The dimorphism in bone structure undermines the assumption that estrogens are the only sex steroids needed for bone formation, since estradiol works simi- larly in men and women. Observed differences between sexes have led to the hypothesis that the local action and balance of androgens and estrogens at the cellular level can better explain clinically observed differences [28].

Estrogens originate from androgens in two predominant pathways. The adrenals produce large amounts of DHEA, DHEAS, and androstenedione; these androgens can be converted to testosterone through activity of $17-\beta$ hydroxysteroid dehydrogenase (17- $\beta$-HSD), $3-\beta$-HSD, and steroids sulfatase [36]. It has been shown that the enzymes (aromatase CYP19, and $17-\beta-$ HSD) necessary for conversion of androgens to estrogens are localized in the bone, indicating that local conversion is necessary for normal bone structure [37]. The importance of local conversion of androgens to estradiol may explain difficulties in linking the serum levels of sex steroids to the risk of osteoporosis in men [38,39].

Estrogen receptor (ER) has been identified in the growth plates of humans and rodents, in the osteoblasts and osteocytes, but is absent in osteoclasts [40-42]. Estrogens (through ER $\alpha$ ) stimulate osteoblast proliferation and expression of cytokines, bone protein matrix, and transcription factors. Although ER $\alpha$ is expressed in osteoclasts of some species, $\mathrm{ER} \beta$ is expressed in osteoclasts of most studied animals and humans. Thus, to explain the suppression of bone resorption seen with estradiol treatment, estradiol must act through osteoblast receptors and not through a direct effect on the osteoclast in humans (Figure 1) [43].

The effect of androgens on bone metabolism is complex. Androgen receptor (AR) is expressed at higher levels in periosteal space in men, the area of most significant male bone growth [44]. Significant crosstalk between osteoblasts, osteoclasts, and macrophages exist, and this signaling is critical to sustaining normal bone metabolism. TGF- $\beta$, insulin growth factor (IGF) and interleukin- 6 are the main androgen-dependent regulators of osteoblast and osteoclast activity. Testosterone treatment increases TGF- $\beta$ levels in bone and orchiectomy decreases its expression [45]. Insulin-like growth factors are under modulatory effects of PTH and androgens. Low androgen levels are associated with decreased levels of IGF and decreased growth velocity [46,47]. Deficiency in IGF results in early loss of bone mass [48]. Interleukin-6 mediates osteoclastogenic activity and bone resorption in hypogonadism and testosterone replacement therapy suppresses IL-6 expression.

Androgen receptor is expressed in osteoblasts of rats and mice, however it is not expressed in human osteoclasts. This supports the clinical observation that androgens are most responsible for periosteal bone growththus estrogens and androgens stimulate formation of new bone in different areas. Through indirect effect on the osteoclast, estradiol decreases the osteoclast-driven resorption 
[49]. In humans and rodents, it is known that estrogens have negative effect on osteoclasts related bone resorption, however it is not clear if estrogens have direct or indirect effect on osteoclast differentiation and mobilization. Androgen receptor is specifically expressed in the growth plates and cartilages of males and females and its expression is especially high during puberty [44]. In experimental settings, the injection of testosterone into the bone growth plate results in significant proliferation and increase in size of the growth plate; this indicates that androgens together with growth hormone are responsible for linear bone growth acceleration seen during puberty. Expression of both the AR and ER decreases after puberty. Through AR, androgens increase bone length and thickness during puberty; subsequent closure of epiphyses and cessation of growth is under the control of estrogen.

In adult orchiectomized rats, loss in bone mineral density with loss of cortical mass can be reversed by testosterone or estradiol replacement [50]. Treatment with aromatase inhibitor has decreased trabecular bone mass but has minimal effect on cortical bone area in intact male rats [30,51]. Selective estradiol receptor modulators (SERMs) increase cortical and trabecular bone mass in orchiectomized rats and increases trabecular bone mass in intact males [52,53]. DHEA and androstenedione increase trabecular bone formation in ovariectomized rats. Five $\alpha$-reductase inhibitors or androgen receptor antagonists have no or minimal effect on cortical bone area. This is important to remember when choosing medications to modulate hypothalamic-pituitary-testicular axis in men.

Although experimental data in vitro and in vivo strongly supports a role of androgens in bone function, epidemiological studies differ in their conclusions [54, 55]. The main difficulties in interpretation of epidemiological data using serum testosterone and estradiol levels as predicting factors of bone mineral density stem from methodological differences in measuring sex steroids, applied ranges of norms and inert limits of detection using commonly available commercial kits. Serum levels of testosterone using a standardized sample in proficiency testing may vary by $30 \%$ between different clinical laboratories [56,57]. This significant lack of accuracy may drastically affect the statistical analysis. Estradiol is even more difficult to measure in men because its molar concentration is 5000 times lower than concentrations of testosterone and often estradiol levels measured in men reach the limits of reliable detection [58]. Thus it is recommended that the most accurate method of sex steroid measurement like liquid chromatography/mass spectroscopy (LC/MS) is used to measure estradiol and testosterone during evaluation and in future clinical research. ARUP laboratories offer testosterone measurement using the LC/MS method and age adjusted norms which correlate very well with established norms based on healthy, fertile male population [59].

In summary, androgens and estrogens play a critical role in normal bone function and structure in men, low testosterone is associated with lower levels of estradiol and a direct negative effect on bone mineral density. Hypogonadal men are therefore at significant risks for complications related to low bone mineral density.

4) Risk factors for osteoporosis and preventative measures.

Most previous studies about low BMD risk factors concentrated on older men and not on men of reproductive age. Aging and genetic background have been considered main risk factors for low BMD in older men, however based on our experience and growing epidemiological data, it seems that low testosterone may be a leading cause of low BMD in younger men who present with infertility and erectile dysfunction [60]. Prolonged use of glucocorticosteroid (GCS), equivalent of $5 \mathrm{mg}$ of prednisone daily for minimum of 6 months, is clearly associated with low testosterone and decrease in bone mineral density [61]. Preventative measures include normalization of testosterone level, vitamin D3 supplementation and bisphosphonates. These should be instituted early on in men who are on chronic GCS therapy. Common anticonvulsant therapy like phenytoin and phenobarbital increase hepatic metabolism of vitamin $\mathrm{D}$, with subsequent decreased intestinal absorption of calcium. Calcium supplementation with vitamin D3 should be started early; if osteopenia is confirmed one can consider bisphosphonate or teriparatide therapy. Hypogonadism in men is strongly associated with increased risk of decreased bone mineral density. Excessive alcohol use and tobacco smoking is associated with low BMD in both men and women. Tobacco-related bone loss is most likely secondary to overall lower body mass; however direct effect on bone mineralization is possible. Alcohol consumption has a bell-response curve with low and high consumption associated with decreased BMD; moderate consumption may actually have a protective effect. Effects of excessive alcohol use are often most related to poor nutrition status and decreased physical activity, although direct detrimental effect on osteoblasts has been shown as well $[62,63]$.

5) Diagnosis and evaluation of osteopenia and osteoporosis.

Osteopenia and osteoporosis are defined as bone mass lower than expected based on reference group adjusted for sex, age, and race. Peak BMD is achieved during puberty and early adulthood; with aging, progressive changes in calcium intake, vitamin D levels, declining sex steroid production and exercise level causes loss in both trabecular and cortical bone. Presence of osteoporosis 
indicates increased risk of complications like hip, radius and spine fractures [64].

Bone mineral density measures bone mineralization (calcification) per gram of bone. In clinical practice, BMD is not measured directly but indirectly by measuring bone absorption of X-rays. Heavy minerals like calcium will absorb certain amount of radiation and its absorption is proportional to amount of heavy cations per volume unit. Since calcium is the most abundant mineral in bone, the densitometry measures predominately calcium content per volume unit. The BMD is an absolute value and it is used to follow changes in BMD over time-especially in assessing response to treatment [65].

Most older men are diagnosed with osteopenia or osteoporosis because of history of minimal impact fractures, vertebral body or hip fracture, as opposed to women, who often are diagnosed during screening for osteoporosis [65]. There is no commonly accepted guideline for screening for osteoporosis in younger men and it is likely that the screening of entire population of men is not cost-effective [66]. However, the literature regarding osteopenia and osteoporosis in men focuses exclusively on older men and not men of different ages. One cannot generalize findings and recommendations from studies in older men to the population of younger men. For example, the prevalence of osteoporosis in young men with low testosterone is quite high. The association between low levels of sex steroids and increased risk of osteoporosis is well established and thus screening in men should focus on at risk groups: men with history of minimal impact fractures of hip, vertebral bodies, or distal radius, men with hypogonadism, chronic steroid treatment and disorders listed as high and moderate risk in Table 1.

The diagnosis of low mineral bone density has to be established using objective measurements [67]. The most commonly used methods of screening for osteoporosis are dual-energy X-ray absorptiometry (DEXA scan), and quantitative ultrasound of the heel. Quantitative CT scan $\mathrm{X}$-ray absorptiometry is used in research. The DEXA scan is approved for both men and women for screening for low BMD, as well as for monitoring therapy. Ultrasound of the heel is not approved as a means of monitoring therapy in the United States. Although ultrasound-based equipment is easy to use and has no radiation exposure, the norms for younger men have not been established. In groups of older men (>65), the heel quantitative ultrasound is almost as good as DEXA scan in predicting risk of hip or vertebral fractures [68].

The DEXA scan measures BMD in the lumbar spine and in the hips and the absolute measurements are compared to established, age adjusted population-based norms. Three measurements are commonly used and reported: absolute BMD, $\mathrm{T}$ score and $\mathrm{Z}$ score. The $\mathrm{T}$ score reflects the deviation of patient's BMD from peak
Table 1. Stratification of risk factors may aid in the decision about the screening for low BMD.

\begin{tabular}{|c|c|}
\hline \multicolumn{2}{|c|}{$\begin{array}{l}\text { Common factors affecting risk for developing osteopenia and } \\
\text { osteoporosis }\end{array}$} \\
\hline \multicolumn{2}{|l|}{ High Risk } \\
\hline & Previous history of low impact fractures \\
\hline & $\begin{array}{l}\text { Abnormal DEXA scan (T score and Z score } \\
\text { lower than } 1 \text { SD from norm) }\end{array}$ \\
\hline & Chronic glucocorticosteroid use \\
\hline & Hypogonadism \\
\hline & Hyperparathyroidism \\
\hline & Anti androgen therapy \\
\hline \multicolumn{2}{|c|}{ Moderate Risk } \\
\hline & Alcohol abuse \\
\hline & Smoking \\
\hline & Family history of osteoporosis \\
\hline & Multiple myeloma, lymphoma \\
\hline & Rheumatoid arthritis \\
\hline & Thyroid dysfunction \\
\hline & Anticonvulsant therapy \\
\hline \multicolumn{2}{|l|}{ Low Risk } \\
\hline & Gastric resection and gastric bypass \\
\hline & Chronic liver and renal failure \\
\hline & Low body mass index \\
\hline & Pernicious anemia \\
\hline
\end{tabular}

BMD adjusted for sex and race; i.e. the deviation from BMD of young healthy men in their twenties. The $T$ score is a good predictor of risk for hip and other fractures in both men and women and has been commonly used in studying osteoporosis in older men. The $\mathrm{Z}$ score is a measure of patient's BMD compared to other normal subjects for sex, race and age, and assesses if the low bone mineral density is caused by other factors than age. Thus if an individual's T score is low early in life, it may indicate that one has never achieved the optimal peak $\mathrm{BMD}$, and although the annual rate of BMD decline may be normal, BMD will fall-2 standard deviations (SD) from the optimal BMD at earlier age in men with low peak BMD. Low $\mathrm{Z}$ score indicates that other conditions than age-like low testosterone, heavy alcohol consumption or hyperparathyroidism contribute to decline in BMD expected for that age group.

It is important to remember that the definitions of osteopenia and osteoporosis have been established based on population studies of women. The WHO defines osteopenia as a BMD expressed as $\mathrm{Z}$ or $\mathrm{T}$ score which is 1 
SD below the mean BMD. Decrease in BMD by one standard deviation from mean increases risk of hip fracture by close to 3 times. Osteoporosis is defined as $\mathrm{Z}$ or $\mathrm{T}$ scores below 2.5 SD of the mean. The WHO definition and $\mathrm{Z}$ and $\mathrm{T}$ cutoffs have been adopted for diagnosis of osteoporosis among older men, but no large epidemiological data exist in men younger than 50 , however based on increased risk of fractures in men with $\mathrm{T}$ scores below -2 , it is commonly accepted that men with $\mathrm{T}$ score $<-2$ should be offered treatment, especially if other risks factors-such as hypogonadism-are present [69].

\section{5) Laboratory evaluation}

In our practice, men with low testosterone undergo DEXA scan and men who are found to have low bone mineral density undergo further laboratory evaluation to exclude other causes for low BMD. In general medical practice, screening for low BMD is usually offered to men older than 65 or may be offered to younger men if they have any risks factors. The latter group should have sex steroids measured in addition to standard panel of laboratory tests. The initial laboratory evaluation of men who have low BMD may include $\mathrm{CBC}$, complete metabolic panel to assess renal and liver function, calcium, phosphorus, vitamin D, bone alkaline phosphatase, thyroid panel, parathyroid hormone level (PTH), estradiol level, 24-h urine calcium collection. Serum electrophoresis is used to screen for multiple myeloma. Low vitamin $\mathrm{D}$ is associated with elevated PTH; adequate supplementation over 3 months will usually correct elevated PTH. Cholecalciferol [D3) is an endogenous form of vitamin D, whereas ergocalciferol vitamin D2 is provided in commonly available preparations. Vitamins D3 and D2 can be reliably measured in serum and used to monitor adherence to therapy-especially in younger men who often forget about taking their medications. Optimal levels of $25(\mathrm{OH})_{2} \mathrm{D}$ fall between 30 to $80 \mathrm{ng} / \mathrm{ml}$. Formation of the bone may be measured using tartrate resistant acid phosphatase (TRAP), and products of collagen and protein matrix degradation: cross-linked N-telopeptide (NTx), C-telopeptide (CTx), deoxypyridinoline, pyridinoline, and hydroxyproline. Bone-specific alkaline phosphatase is elevated in osteoporosis, osteomalacia, Paget's disease, and primary hyperparathyroidism. ALP can be used to monitor therapy [70].

6) Treatment

Management of low BMD in men with hypogonadism is within the scope and abilities of the general endocrinologist and urologist who both receive training in calcium metabolism and reproductive endocrinology during residency and fellowship training. Input from an endocrinologist specializing in male osteoporosis may be needed in primary osteoporosis or failure of treatment.

Despite the lack of treatment standards for low BMD in young, hypogonadal men $(<50)$ of reproductive age, the goal of treatment is to decrease risk of hip and vertebral fractures, to prevent further loss of BMD, and to increase BMD and improve quality of life. Treatment of low BMD has to be based on the most likely established etiology and imminent risk of hip fracture, as well as patient's reproductive plans.

In hypogonadal men testosterone replacement therapy increases BMD and should be considered as initial therapy, especially in younger men [71]. Testosterone replacement therapy doesn't increase BMD in eugonadal men, which is often a reason of confusion about the role of testosterone replacement therapy in men with low BMD. In older hypogonadal men one needs to balance the risks and benefits of each form of therapy and limit testosterone treatment to men who are clearly hypogonadal. Considering that the estradiol level in both men and women has high predictive value for the bone mineral density, it is important to choose forms of therapy which do not lower available estradiol level.

All men should increase their calcium intake to 1 to $1.5 \mathrm{~g}$ a day; recommended vitamin $\mathrm{D}$ intake in men with low BMD should be 800 IU to 1000 IU a day. Vitamin D levels depend on normal synthesis in skin, oral intake, and normal gastrointestinal absorption. Decreased exposure to sun-which can be socially preferably in some communities-lowers vitamin D levels and may require supplementation. Weight bearing exercise and increase in lean body mass have a positive effect on circulating testosterone levels, and reduces risk of fractures by $25 \%$. Moderate alcohol consumption and smoking cessation are important factors in preventing further BMD decline.

\section{Androgens}

Hypogonadism results in net negative trabecular bone mass loss which starts within days after orchiectomy. On average, men lose up to $10 \%$ of BMD in lumbar spine within 1 year after orchiectomy [72]. In vitro and in vivo animal studies have strongly supported the role of testosterone replacement in preventing post orchiectomy bone loss; adequate length of treatment may restore normal BMD. Hypogonadism is metabolically similar to highturnover osteoporosis since the induction of osteoclasts and resorptive activity is followed by increase in bone formation; however in prolonged hypogonadal states the net result is progressive loss of bone mass. The lumbar spine, which is predominantly trabecular in structure, is affected first by hypogonadism [73]. Aromatizable androgens like testosterone, DHEA, and androstenedione can prevent bone loss at much lower levels, than nonaromatizable androgens like DHT which need to be given in supraphysiological amounts to affect BMD. Thus optimal androgen replacement should be potent, and aromatizable, and at the same time not converted to DHT to avoid prostate enlargement and side effects 
related to BPH. Therapy with testosterone is indicated in symptomatic men with hypogonadism [74]. Androgens have also non-direct skeletal effects which affect BMD. The growth hormone (GH) axis, especially amplitude of GH release, is regulated by androgens. Decreases in IGF-1, and loss of muscle strength, decreases mechanical strain and contribute to decreased BMD. The increase in muscle mass seen during puberty enhances mechanical loading and stimulates skeletal modeling, which underscores the importance of exercise and normal testosterone levels during puberty.

Form, dosage, and timing of testosterone replacement therapy varies between different preparations, however regardless of the preparation used, the therapy should achieve high normal levels of testosterone. Therapy with testosterone is only indicated in men with hypogonadism since improvement in BMD is inversely related to pretreatment testosterone levels [75,76]. AndroGel pump allows for easy dosing in broad range of patients. AndroGel has optimal pharmacological properties and restores normal physiological levels of testosterone $[77,78]$. AndroGel is also well tolerated by patients and devoid of the musk-like smell which is characteristic of Testim. Injectable testosterone (cypionate, enanthate) has been used successfully in men with hypogonadism and osteoporosis, but the surge in testosterone level for first couple days after injection has been linked to polycythemia, mood swings, and sodium retention and increase in blood pressure, thus side effects of injectable form of testosterone replacement need to be balanced against the benefits [77]. However, side effects of injectable testosterone are not found in every patient, and some patients may prefer an intermittent visit to their provider for an injection rather than daily dosage at home. Concerns about gel transfer to partners or children and the lower cost of IM (intra-muscular) testosterone may also influence a patient's decision to use the injectable preparation. Androderm can also be considered for testosterone replacement but more than 1:10 men will develop skin irritation from the patch.

The effectiveness of testosterone therapy in men with low BMD has been established in most studies of hypogonadal men, although the mean increase in BMD varies from $3 \%$ to $14 \%$ in lumbar spine. In a study of 72 hypogonadal men treated up to 16 years with testosterone, all men achieved long term and sustainable increase in BMD, with most evident increase in men who had low initial BMD [75]. Lumbar spine and other trabecular bones respond better to TRT (testosterone replacement therapy) than cortical bones like hip [79]. The increase in lean body mass during TRT may have additional positive effect on bone mass in men.

Although further studies are needed, it seems that higher levels of testosterone are needed to improve BMD in men with idiopathic hypogonadotropic hypogonadism (IHH) [80]. This observation together with reports that delayed testosterone therapy in men with Klinefelter syndrome diminishes the gain in BMD may indicate that the adolescents with delayed puberty, IHH, Kallmann syndrome and Klinefelter syndrome may benefit from early assessment of BMD and early treatment of hypogonadism to achieve expected peak bone mineral density [81,82].

It is unclear if higher doses of testosterone replacement therapy increase BMD faster than more moderate doses, although some studies suggest modest differences in BMD gain in trabecular bones with use of high dose of Sustanon ( $250 \mathrm{mg}$ weekly v. monthly). Wang showed modest improvement in BMD in spine using topical testosterone $-2 \%$, which could suggest that the supraphysiological levels of testosterone result in quicker improvement in BMD, but because of high heterogenicity of patients in each study, it is hard to draw solid conclusions since the pharmacokinetics of each testosterone replacement forms may contribute to observed differences in BMD changes. It is prudent for now to aim at achieving testosterone serum levels in high normal quartile [83].

In our practice we aim at achieving testosterone levels in upper normal levels. All adult patients not pursuing infertility treatment are started on $10 \mathrm{~g}$ of AndroGel (8 depressions of pump) and testosterone levels are checked using LC/MS 4 weeks after initiation of therapy and the dose adjusted to keep testosterone level in upper quartile. The CBC, CMP, PSA, and lipids are checked before the initiation of therapy and during semiannual follow-up visits. The BMD is rechecked after 12 months of therapy and increase in BMD by $3 \%$ is considered a significant response. Increases in testosterone may have positive impact on sexual performance and lean body mass.

Although DHEA levels decreases with age, DHEA supplementation increased trabecular bone mass in women but had no effect in healthy men $[84,85]$. DHEA decreases IL-6 and thus may have mild positive effect in men after orchiectomy, but it is unknown if DHEA supplementation in younger men and identified low DHEA will have any positive effect on BMD. Androstenedione supplementation has not been studied in clinical trials and thus can't be recommended at this time.

Regardless of the method of androgen replacement, increase in calcium and vitamin D intake is an important adjuvant form of therapy which should be instituted in every man with low BMD [86].

\section{Selective Estrogen Receptors Modulators (SERMs)}

For men who are currently trying to conceive, testosterone is a poor option since it lowers FSH and LH. SERMs like clomiphene citrate may be a better option in younger 
group. SERMs have positive antiresorptive properties by acting on ER receptors and increase in testosterone level stimulates bone formation. SERMs are being actively investigated as a promising method of treatment of osteoporosis in men with history of prostate cancer [87]. Clomiphene citrate increases FSH and LH, thus having positive effect on spermatogenesis, testosterone level and at the same time has a known positive effect on bone mass. Unfortunately, available studies were not long enough to measure changes in BMD using DEXA and biochemical markers of bone metabolism were used instead. Abnormal bone markers are rarely seen in population of hypogonadal young men, thus changes in BMD have to be used for the objective assessment of efficacy of treatment. Furthermore, one should avoid lowering estradiol for longer than 12 months in men with osteoporosis since it is known that low estradiol levels contribute to decreased BMD.

Because of the lack of any strong evidence of improvements in BMD in men on SERMs, risks and potential benefits need to be considered. A Basic understanding of the roles of ER and AR signaling in the bone physiology in men, make SERMs and AR modulators an exciting target for new therapeutic modalities in men with osteoporosis, although further studies must be done to evaluate their optimal roles in patients with low BMD [88].

\section{Bisphosphonates}

In men who do not respond to androgen replacement therapy, or have recent history of prostate cancer and osteoporosis with $\mathrm{T}$ score $<-2.0$, therapy with bisphosphonates is indicated $[87,89]$. Bisphosphonates (BSN) are structurally related to pyrophosphates and all available bisphosphonates have similar chemical backbone with R1 and R2 functional groups. The R1 group works by enhancing binding to hydroxyapatite and the R2 group is responsible for inhibition of resorption [90,91]. Although BSNs were initially believed to act mainly through the mechanical inhibition of osteoclasts, it is now known that BSNs have diverse effects on osteoclast metabolic activity through inhibition of protein tyrosine phosphatases, disruption of small GTPases signaling, their ability to decrease activity of $\mathrm{H}+$ ATPase and effect on the cytoskeleton with the sum effect of BSNs action inducing apoptosis and suppression of resorption of osteoclasts $[92,93]$.

Differences in the R2 functional group result in disruption of different pathways and R2 substitutions are responsible for differences in BSNs activity in vitro and in vivo. The structural properties of BSNs allow them to bind to the surface of calcium phosphate and inhibit growth and dissolution of mineral bone structure [93]. Once bound and incorporated in the bone, it may take many years to completely wash out the BSNs and low circulating levels of BSN are found for months after withdrawal of therapy. The long term binding and incorporation of BSN into calcium phosphate may be less desired property in younger men who have long life span ahead of them, since the long terms effects of BSNs on reproduction are poorly understood. Some of bisphosphonates negatively affect male and female fertility and FDA labeling for Fosamax and Boniva lists decreased female fertility, implementation rate, increased preimplantation loss and prolonged parturition with treatment related deaths (see FDA approved drug insert). The negative effects on female fertility are believed to be secondary to decreased calcium levels. Fosamax does not have a negative effect on male fertility but doses used in reported preapproval studies were similar to doses normally used in humans. Male rats treated with Boniva (at much higher dose than normally recommended $>40 \times$ ) for 28 days experienced decreased sperm density and sperm morphology (package information). Although doses used in animal experiments were higher than recommended does in men, at this point it is prudent to avoid bisphosphonates in younger men who are treated for infertility. Normal calcium metabolism is necessary for normal sperm activity and lowering the available calcium levels can have a negative impact on sperm function. There are no published studies evaluating the effects of bisphosphonates on human reproduction. Bisphosphonates have been shown to reduce bone loss, increase BMD in postmenopausal women and in hypogonadal men, as well as in glucocorticosteroid induced osteoporosis [94,95]. Alendronate (Fosamax) is approved in USA for use in men and has been shown to increase BMD with a trend toward reduction of non-vertebral and vertebral fracture risk [96]. Risedronate (Actonel] is often used in men with chronic steroid use and it has been shown to increase BMD in men as well [97,98].

Zoledronic acid has not been approved for use in prevention or treatment of osteoporosis in men. Its use should be restricted to men with metastatic prostate cancer, and multiple myeloma when pamidronate is preferable as per Mayo Clinic consensus statement [99]. Because of very long half life after binding to bone, risk of osteonecrosis of jaw and reported impairment of renal function zoledronic acid should not be used in men in reproductive age since the risks outweigh the potential benefits $[99,100]$.

Bisphosphonates have side effects which depend mostly on R2 functional group. Both pamidronate and alendronate given orally can cause esophagitis erosions and ulcerations. Most of BSNs with amine group cause nausea, dyspepsia, vomiting, gastric pain, and diarrhea. Because of growing concerns about side effects related to long term use of bisphosphonates, the indication and need for therapy should be reviewed at least annually 
based on results of DEXA scans and therapy discontinued if treatment objectives are met [101].

\section{Anabolic Hormones \& Other Treatments}

\subsection{Growth Hormone}

Prepubertal and pubertal bone growth depends on GH-IGF-1 system, as evident by short stature in children and adolescent with growth hormone deficiency. Deficiency in GH results in loss of cortical bone mass but preservation of trabecular bone, which depends more on estradiol action [102]. Androgens stimulate GH release through their aromatization to estrogens in brain. Low doses of estradiol stimulate $\mathrm{GH}$ and high estrogens level suppresses the GH release. GH therapy is indicated in men with low IGF-1 levels; however the experience in GH therapy in men with osteoporosis is limited [103].

Teriparatide, recombinant parathyroid hormone, has been approved for use in men with high risk for fractures. In one study daily subcutaneous injections of $20 \mathrm{mcg}$ of Forteo increased BMD in lumbar spine by $5.9 \%$, but inadequate data exist about reduction of hip and vertebral fractures in men with osteoporosis. Teriparatide can be used for short time since it has significant and fast anabolic action, but once therapy is stopped therapy with bisphosphonates are recommended since further gains in BMD can be achieved. This form of therapy needs to be closely monitored and is contraindicated in primary hyperparathyroidism, Paget's disease of bone, osteomalacia, renal failure, nephrolithiasis, elevated calcium or alkaline levels. Teriparatide can be used up to two years and response needs to be assessed with DEXA scan [104-106].

Thiazide diuretics are useful in men with persistent urinary calcium loss, despite of correction of low vitamin D levels. Long term use of thiazide diuretics can lower risks of hip fractures.

\subsection{Experience in Our Practice}

In search of better guidance for the screening and treatment of low BMD in younger men, we have conducted studies at our own practice. The aim of this study was to analyze risk factors for osteopenia or osteoporosis in younger, ( $<55$ year old) hypogonadal men seeking care at an andrology practice.

\subsection{Methods}

This study was prospective, observational, IRB approved study. Patients $(\mathrm{n}=199)$ referred because of infertility (50\%), hypogonadism (20\%), sexual dysfunction $(27 \%)$, or chronic pelvic pain $(3 \%)$ were seen by a single physician. Serum testosterone was measured using liquid chromatography-mass spectrometry; LH, FSH, PRL, and estradiol were evaluated using chemiluminescence assays.
Bone mineral density (BMD) was measured using new generation Prodigy GE DEXA scanner with race, sex, and age adjusted normograms. Osteopenia was defined as having a $\mathrm{T}$ or $\mathrm{Z}$ score below -1 , and osteoporosis as $\mathrm{T}$ or $Z<-2.5$. The age, height, weight, adjusted BMD and $\mathrm{T}$ and $\mathrm{Z}$ scores were recorded. One-way ANOVA with Tukey post-test and unpaired student $\mathrm{T}$ tests were performed with GraphPad Prism version 5.00 for Windows, GraphPad Software, San Diego California USA.

\subsection{Results}

One hundred ninety nine men were enrolled, and mean total testosterone was $<300 \mathrm{ng} / \mathrm{dl}$. Patients were divided into three groups based on their DEXA scan results; normal bone density $(\mathrm{n}=122,57 \%)$, osteopenia $(\mathrm{n}=69$, $39 \%)$ and osteoporosis $(n=8,4 \%)$. There were no differences in the mean age $(p<0.64)$, height $(p<0.99)$ and weight $(\mathrm{p}<0.06)$ among the three groups (ANOVA), but men with osteopenia had statistically significant lower weights lower weight $(\mathrm{p}<0.02)$. The mean testosterone levels of men with osteopenia and normal BMD were similar (295.1 ng/dl vs $282.3 \mathrm{ng} / \mathrm{dl} \mathrm{p}<0.24)$; however there was a significant difference in $\mathrm{T}$ levels between men with osteoporosis and osteopenia and normal men (171.0 v. 295.1 v. $282.3 \mathrm{ng} / \mathrm{dl}, \mathrm{p}<0.007)$. There were no significant differences among mean estradiol levels $(\mathrm{p}<$ 0.844 ), mean FSH levels ( $p<0.02$ ) or mean LH levels ( $p$ $<0.379$ ) between the three groups. When comparing mean $\mathrm{T}$ and $\mathrm{Z}$ scores, mean lumbar $\mathrm{T}$ scores were significantly different among the three groups of patients ( $p$ $<0.0001)$. Men with infertility had statistically significant lower $\mathrm{T}$ than men with hypogonadism and $\mathrm{ED}$ (Figure 3).

\section{Conclusion}

Low bone mineral density is common in young hypogonadal men seen in urological practice. Testosterone levels $<200 \mathrm{ng} / \mathrm{dl}$ increases risk for osteoporosis, however neither testosterone nor estradiol, FSH, LH and PRL are able to assess the risk of osteoporosis, osteopenia, or normal bone density. As a result of the poor predictive qualities of these values, all hypogonadal men should have a DEXA scan. Hypogonadal men are at high risk for osteopenia and osteoporosis; patients should not be excluded from screening based on moderate levels of testosterone.

\section{Future Prospects and Summary}

Prevalence of osteoporosis in younger men is as high as in epidemiological screening of men over 50 , it will be critical to answer if early detection and correction of low testosterone and low vitamin D3 can decrease prevalence of osteoporosis, vertebral and non-vertebral fractures. 

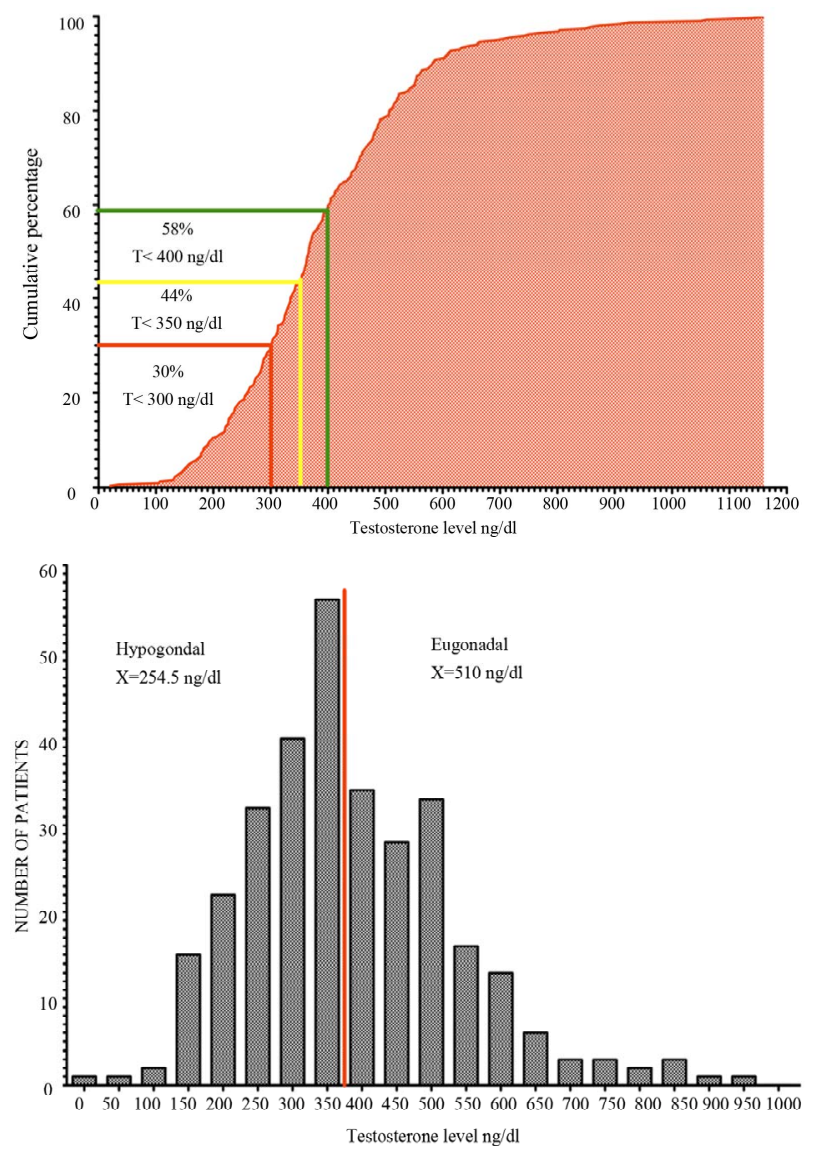

Figure 3. Cumulative frequency distribution (up) and histogram (down) of serum testosterone level in 323 men between 18 and 65 (mean age: 40) who presented with infertility or sexual dysfunction. All men had testosterone level measured using LC/MS in the same commercial laboratory.

Normal men start to develop osteoporotic fractures 10 years later than females and it is unknown if men who are diagnosed earlier will have decreased frequency of fractures. It is clear that men who present with infertility or sexual dysfunction and have low testosterone should be screened for osteoporosis. Men with osteoporosis and low testosterone should be treated although the optimal method of treatment and length of treatment requires further studies and should be tailored to the medical needs of the patient. Testosterone replacement therapy in this group of men may not only have positive effect on their bone density but also improve their sexual function, lean body mass and quality of life.

We hope that above review and presented data about prevalence of hypogonadism and osteoporosis in younger men brings further interest among clinicians and scientists.

\section{REFERENCES}

[1] L. Gennari and J. P. Bilezikian, "Osteoporosis in Men:
Pathophysiology and Treatment," Current Rheumatology Reports, Vol. 9, No. 1, 2007, pp. 71-77. doi:10.1007/s11926-007-0025-y

[2] L. J. Melton 3rd, E. A. Chrischilles, C. Cooper, A. W. Lane and B. L. Riggs, "Perspective How Many Women Have Osteoporosis?" Journal of Bone and Mineral Research, Vol. 7, No. 9, 1992, pp. 1005-1010. doi:10.1002/jbmr.5650070902

[3] L. Gennari and J. P. Bilezikian, "Osteoporosis in Men," Endocrinology and Metabolism Clinics of North America, Vol. 36, No. 2, 2007, pp. 399-419. doi:10.1016/j.ecl.2007.03.008

[4] C. Cooper, G. Campion and L. J. Melton 3rd, "Hip Fractures in the Elderly: A World-Wide Projection," Osteoporosis International, Vol. 2, No. 6, 1992, pp. 285-289. doi:10.1007/BF01623184

[5] E. Seeman, G. Bianchi, S. Khosla, J. A. Kanis and E. Orwoll, "Bone Fragility in Men-Where Are We?" Osteoporosis International, Vol. 17, No. 11, 2006, pp. 1577 1583. doi:10.1007/s00198-006-0160-8

[6] A. A. Abbasi, D. Rudman, C. R. Wilson, P. J. Drinka, S. N. Basu, D. E. Mattson and T. J. Richardson, "Observations on Nursing Home Residents with a History of Hip Fracture," The American Journal of the Medical Sciences, Vol. 310, No. 6, 1995, pp. 229-234.

[7] T. J. Allain, "Prostate Cancer, Osteoporosis and Fracture Risk," Gerontology, Vol. 52, 2006, pp. 107-110. doi:10.1159/000090956

[8] N. McLeod, C. C. Huynh and P. Rashid, "Osteoporosis from Androgen Deprivation Therapy in Prostate Cancer Treatment," Australian Family Physician, Vol. 35, No. 4, 2006, pp. 243-245.

[9] J. A. Kanis, O. Johnell, A. Oden, C. De Laet and D. Mellstrom, "Diagnosis of Osteoporosis and Fracture Threshold in Men," Calcified Tissue International, Vol. 69, No. 4, 2001, pp. 218-221. doi:10.1007/s00223-001-1046-6

[10] A. C. Looker, E. S. Orwoll, C. C. Johnston Jr., R. L. Lindsay, H. W. Wahner, W. L. Dunn, M. S. Calvo, T. B. Harris and S. P. Heyse, "Prevalence of Low Femoral Bone Density in Older U.S. Adults from NHANES III," Journal of Bone and Mineral Research, Vol. 12, No. 11, 1997, pp. 1761-1768. doi:10.1359/jbmr.1997.12.11.1761

[11] L. J. Melton 3rd, "The Prevalence of Osteoporosis: Gender and Racial Comparison," Calcified Tissue International, Vol. 69, No. 4, 2001, pp. 179-181. doi:10.1007/s00223-001-1043-9

[12] L. M. Marshall, J. M. Zmuda, B. K. Chan, E. BarrettConnor, J. A. Cauley, K. E. Ensrud, T. F. Lang and E. S. Orwoll, "Race and Ethnic Variation in Proximal Femur Structure and BMD among Older Men," Journal of Bone and Mineral Research, Vol. 23, No. 1, 2008, pp. 121-130. doi: $10.1359 / \mathrm{jbmr} .070908$

[13] C. Cooper, "The Crippling Consequences of Fractures and Their Impact on Quality of Life," The American Journal of Medicine, Vol. 103, No. 2A, 1997, pp. 12S$17 \mathrm{~S}$, discussion $17 \mathrm{~S}-19 \mathrm{~S}$.

[14] L. Forsen, A. J. Sogaard, H. E. Meyer, T. Edna and B. Kopjar, "Survival after Hip Fracture: Short- and Long- 
Term Excess Mortality according to Age and Gender," Osteoporosis International, Vol. 10, No. 1, 1999, pp. 7378. doi:10.1007/s001980050197

[15] C. Becker, "Pathophysiology and Clinical Manifestations of Osteoporosis," Clinical Cornerstone, Vol. 8, No. 1, 2006, pp. 19-27. doi:10.1016/S1098-3597(06)80062-1

[16] E. L. Smith and D. M. Raab, "Osteoporosis and Physical Activity," Acta Medica Scandinavica Supplementum, Vol. 711, 1986, pp. 149-156.

[17] P. Garnero and P. D. Delmas, "New Developments in Biochemical Markers for Osteoporosis," Calcified Tissue International, Vol. 59, No. 1, 1996, pp. S2-S9. doi: $10.1007 / \mathrm{s} 002239900168$

[18] L. You, S. Temiyasathit, P. Lee, C. H. Kim, P. Tummala, W. Yao, W. Kingery, A. M. Malone, R. Y. Kwon and C. R. Jacobs, "Osteocytes as Mechanosensors in the Inhibition of Bone Resorption Due to Mechanical Loading," Bone, Vol. 42, No. 1, 2008, pp. 172-179. doi:10.1016/i.bone.2007.09.047

[19] G. Silvestrini, P. Ballanti, M. Sebastiani, M. Leopizzi, M. Di Vito and E. Bonucci, "OPG and RANKL mRNA and Protein Expressions in the Primary and Secondary Metaphyseal Trabecular Bone of PTH-Treated Rats Are Independent of That of SOST," Journal of Molecular Histology, Vol. 39, No. 2, 2008, pp. 237-242. doi:10.1007/s10735-007-9158-6

[20] H. Kaji, T. Sugimoto, M. Kanatani, M. Nasu and K. Chihara, "Estrogen Blocks Parathyroid Hormone (PTH)Stimulated Osteoclast-Like Cell Formation by Selectively Affecting PTH-Responsive Cyclic Adenosine Monophosphate Pathway," Endocrinology, Vol. 137, No. 6, 1996, pp. 2217-2224. doi:10.1210/en.137.6.2217

[21] K. H. Lau and D. J. Baylink, "Vitamin D Therapy of Osteoporosis: Plain Vitamin D Therapy versus Active Vitamin D Analog (D-Hormone) Therapy," Calcified Tissue International, Vol. 65, No. 4, 1999, pp. 295-306. doi: $10.1007 / \mathrm{s} 002239900702$

[22] Y. Jayasinghe, S. R. Grover and M. Zacharin, "Current Concepts in Bone and Reproductive Health in Adolescents with Anorexia Nervosa," BJOG: An International Journal of Obstetrics \& Gynaecology, Vol. 115, No. 3, 2008, pp. 304-315. doi:10.1111/j.1471-0528.2007.01601.x

[23] C. Cooper, N. Harvey, K. Javaid, M. Hanson and E. Dennison, "Growth and Bone Development," In: D. J. P. Barker, R. L. Bergmann and P. L. Ogra, Eds., The Window of Opportunity: Pre-Pregnancy to 24 Months of Age, Karger, Basel, 2008, pp. 53-68. doi:10.1159/000113170

[24] P. R. Ebeling "Osteoporosis in Men. New Insights into Aetiology, Pathogenesis, Prevention and Management," Drugs \& Aging, Vol. 13, No. 6, 1998, pp. 421-434. doi:10.2165/00002512-199813060-00002

[25] M. A. Yialamas and F. J. Hayes, "Androgens and the Ageing Male and Female," Best Practice \& Research Clinical Endocrinology \& Metabolism, Vol. 17, No. 2, 2003, pp. 223-236. doi:10.1016/S1521-690X(03)00018-6

[26] E. J. Samelson and M. T. Hannan, "Epidemiology of Osteoporosis," Current Rheumatology Reports, Vol. 8, No. 1, 2006, pp. 76-83.

\section{doi:10.1007/s11926-006-0030-6}

[27] R. Kaaks, S. Rinaldi, T. J. Key, F. Berrino, P. H. Peeters, C. Biessy, L. Dossus, A. Lukanova, S. Bingham, K. T. Khaw, N. E. Allen, H. B. Bueno-de-Mesquita, C. H. van Gils, D. Grobbee, H. Boeing, P. H. Lahmann, G. Nagel, J. Chang-Claude, F. Clavel-Chapelon, A. Fournier, A. Thiebaut, C. A. Gonzalez, J. R. Quiros, M. J. Tormo, E. Ardanaz, P. Amiano, V. Krogh, D. Palli, S. Panico, R. Tumino, P. Vineis, A. Trichopoulou, V. Kalapothaki, D. Trichopoulos, P. Ferrari, T. Norat, R. Saracci and E. Riboli, "Postmenopausal Serum Androgens, Oestrogens and Breast Cancer Risk: The European Prospective Investigation into Cancer and Nutrition," Endocrine-Related Cancer, Vol. 12, 2005, pp. 1071-1082. doi:10.1677/erc.1.01038

[28] D. Vanderschueren, L. Vandenput, S. Boonen, M. K. Lindberg, R. Bouillon and C. Ohlsson, "Androgens and Bone," Endocrine Reviews, Vol. 25, No. 3, 2004, pp. 389 425. doi:10.1210/er.2003-0003

[29] G. E. Krassas and P. Papadopoulou, "Oestrogen Action on Bone Cells," Journal of Musculoskeletal \& Neuronal Interactions, Vol. 2, No. 2, 2001, pp. 143-151.

[30] S. Chowdhury, L. M. Pickering and P. A. Ellis, "Adjuvant Aromatase Inhibitors and Bone Health," Menopause International, Vol. 12, No. 3, 2006, pp. 97-103. doi: $10.1258 / 136218006778234020$

[31] S. Carreau, "Estrogens-Male Hormones?" Folia Histochemica et Cytobiologica, Vol. 41, No. 3, 2003, pp. 107 111.

[32] S. E. Bulun, "Aromatase Deficiency and Estrogen Resistance: From Molecular Genetics to Clinic," Seminars in Reproductive Medicine, Vol. 18, No. 1, 2000, pp. 31-39. doi:10.1055/s-2000-13481

[33] M. E. Jones, W. C. Boon, J. Proietto and E. R. Simpson, "Of Mice and Men: The Evolving Phenotype of Aromatase Deficiency," Trends in Endocrinology and Metabolism, Vol. 17, No. 2, 2006, pp. 55-64.

[34] Q. Wang, M. Alen, P. H. Nicholson, J. M. Halleen, S. L. Alatalo, C. Ohlsson, H. Suominen and S. Cheng, "Differential Effects of Sex Hormones on Peri- and Endocortical Bone Surfaces in Pubertal Girls," The Journal of Clinical Endocrinology and Metabolism, Vol. 91, No. 1, 2006, pp. 277-282.

[35] G. R. Frank, "Role of Estrogen and Androgen in Pubertal Skeletal Physiology," Medical and Pediatric Oncology, Vol. 41, No. 3, 2003, pp. 217-221. doi: $10.1002 / \mathrm{mpo} .10340$

[36] C. Martel, M. H. Melner, D. Gagne, J. Simard and F. Labrie, "Widespread Tissue Distribution of Steroid Sulfatase, 3 Beta-Hydroxysteroid Dehydrogenase/Delta 5Delta 4 Isomerase (3 Beta-HSD), 17 Beta-HSD 5 AlphaReductase and Aromatase Activities in the Rhesus Monkey," Molecular and Cellular Endocrinology, Vol. 104, No. 1, 1994, pp. 103-111. doi:10.1016/0303-7207(94)90056-6

[37] P. G. Blanchard and V. Luu-The, "Differential Androgen and Estrogen Substrates Specificity in the Mouse and Primates Type 12 17beta-Hydroxysteroid Dehydrogenase," Journal of Endocrinology, Vol. 194, 2007, pp. 449- 


\section{5. doi:10.1677/JOE-07-0144}

[38] T. Yanase, S. Suzuki, K. Goto, M. Nomura, T. Okabe, R. Takayanagi and H. Nawata, "Aromatase in Bone: Roles of Vitamin D3 and Androgens," The Journal of Steroid Biochemistry and Molecular Biology, Vol. 86, No. 3-5, 2003, pp. 393-397. doi:10.1016/S0960-0760(03)00349-2

[39] J. M. Janssen, R. Bland, M. Hewison, M. W. Coughtrie, S. Sharp, J. Arts, H. A. Pols and J. P. van Leeuwen, "Estradiol Formation by Human Osteoblasts via Multiple Pathways: Relation with Osteoblast Function," Journal of Cellular Biochemistry, Vol. 75, No. 3, 1999, pp. 528-537. doi:10.1002/(SICI)1097-4644(19991201)75:3<528::AIDJCB16>3.0.CO;2-3

[40] A. M. Cleton-Jansen, H. M. van Beerendonk, H. J. Baelde, J. V. Bovee, M. Karperien and P. C. Hogendoorn, "Estrogen Signaling Is Active in Cartilaginous Tumors: Implications for Antiestrogen Therapy as Treatment Option of Metastasized or Irresectable Chondrosarcoma," Clinical Cancer Research, Vol. 11, 2005, pp. 8028-8035. doi:10.1158/1078-0432.CCR-05-1253

[41] K. Venken, F. Schuit, L. Van Lommel, K. Tsukamoto, J. J. Kopchick, K. Coschigano, C. Ohlsson, S. Moverare, S. Boonen, R. Bouillon and D. Vanderschueren, "Growth without Growth Hormone Receptor: Estradiol Is a Major Growth Hormone-Independent Regulator of Hepatic IGF-I Synthesis," Journal of Bone and Mineral Research, Vol. 20, No. 12, 2005, pp. 2138-2149. doi:10.1359/JBMR.050811

[42] L. Savendahl, "Hormonal Regulation of Growth Plate Cartilage," Hormone Research, Vol. 64, Suppl. 2, 2005, pp. 94-97. doi:10.1159/000087764

[43] S. A. Krum, G. A. Miranda-Carboni, P. V. Hauschka, J. S. Carroll, T. F. Lane, L. P. Freedman and M. Brown, "Estrogen Protects Bone by Inducing Fas Ligand in Osteoblasts to Regulate Osteoclast Survival," The EMBO Journal, Vol. 27, 2008, pp. 535-545. doi:10.1038/sj.emboj.7601984

[44] D. Vanderschueren, J. Gaytant, S. Boonen and K. Venken, "Androgens and Bone," Current Opinion in Endocrinology, Diabetes \& Obesity, Vol. 15, No. 3, 2008, pp. 250254. doi:10.1097/MED.0b013e3282fe6ca9

[45] C. H. Kasperk, G. K. Wakley, T. Hierl and R. Ziegler, "Gonadal and Adrenal Androgens Are Potent Regulators of Human Bone Cell Metabolism in Vitro," Journal of Bone and Mineral Research, Vol. 12, No. 3, 1997, pp. 464-471. doi:10.1359/jbmr.1997.12.3.464

[46] H. Kaji, T. Sugimoto, M. Kanatani, K. Nishiyama, M. Nasu and K. Chihara, "Insulin-Like Growth Factor-I Mediates Osteoclast-Like Cell Formation Stimulated by Parathyroid Hormone," Journal of Cellular Physiology, Vol. 172, No. 1, 1997, pp. 55-62. doi:10.1002/(SICI)1097-4652(199707)172:1<55::AID-JC P6>3.0.CO;2-C

[47] Y. Wang, S. Nishida, B. M. Boudignon, A. Burghardt, H. Z. Elalieh, M. M. Hamilton, S. Majumdar, B. P. Halloran, T. L. Clemens and D. D. Bikle, "IGF-I Receptor Is Required for the Anabolic Actions of Parathyroid Hormone on Bone," Journal of Bone and Mineral Research, Vol. 22, No. 9, 2007, pp. 1329-1337. doi:10.1359/jbmr.070517
[48] T. Niu and C. J. Rosen, "The Insulin-Like Growth Factor-I Gene and Osteoporosis: A Critical Appraisal," Gene, Vol. 361, 2005, pp. 38-56.

[49] H. Michael, P. L. Harkonen, H. K. Vaananen and T. A. Hentunen, "Estrogen and Testosterone Use Different Cellular Pathways to Inhibit Osteoclastogenesis and Bone Resorption," Journal of Bone and Mineral Research, Vol. 20, No. 12, 2005, pp. 2224-2232. doi:10.1359/JBMR.050803

[50] D. Vanderschueren, E. Van Herck, P. Schot, E. Rush, T. Einhorn, P. Geusens and R. Bouillon, "The Aged Male Rat as a Model for Human Osteoporosis: Evaluation by Nondestructive Measurements and Biomechanical Testing," Calcified Tissue International, Vol. 53, No. 5, 1993, pp. 342-347. doi:10.1007/BF01351841

[51] D. Vanderschueren, E. Van Herck, R. De Coster and R. Bouillon, "Aromatization of Androgens Is Important for Skeletal Maintenance of Aged Male Rats," Calcified Tissue International, Vol. 59, No. 3, 1996, pp. 179-183. doi:10.1007/s002239900106

[52] V. C. Jordan, "SERMs: Meeting the Promise of Multifunctional Medicines," Journal of the National Cancer Institute, Vol. 99, No. 5, 2007, pp. 350-356. doi:10.1093/jnci/djk062

[53] C Jochems, U. Islander, A. Kallkopf, M. Lagerquist, C. Ohlsson and H. Carlsten, "Role of Raloxifene as a Potent Inhibitor of Experimental Postmenopausal Polyarthritis and Osteoporosis," Arthritis \& Rheumatism, Vol. 56, No. 10, 2007, pp. 3261-3270. doi:10.1002/art.22873

[54] D. Mellstrom, O. Johnell, O. Ljunggren, A. L. Eriksson, M. Lorentzon, H. Mallmin, A. Holmberg, I. Redlund-Johnell, E. Orwoll and C. Ohlsson, "Free Testosterone Is an Independent Predictor of BMD and Prevalent Fractures in Elderly Men: MrOS Sweden," Journal of Bone and Mineral Research, Vol. 21, No. 4, 2006, pp. 529-535.

[55] A. Rapado, F. Hawkins, L. Sobrinho, M. Diaz-Curiel, A. Galvao-Telles, S. Arver, J. Melo Gomes, N. Mazer, J. Garcia e Costa, H. C. Orcajada, E. Lopez-Gavilanes, M. Mascarenhas, K. Papapietro, M. B. Lopez Alvarez, M. C. Pereira, G. Martinez, I. Valverde, J. J. Garcia, J. J. Carb allal and I. Garcia, "Bone Mineral Density and Androgen Levels in Elderly Males," Calcified Tissue International, Vol. 65, No. 6, 1999, pp. 417-421. doi:10.1007/s002239900726

[56] M. J. Diver, "Analytical and Physiological Factors Affecting the Interpretation of Serum Testosterone Concentration in Men," Annals of Clinical Biochemistry, Vol. 43, 2006, pp. 3-12. doi:10.1258/000456306775141803

[57] W. Rosner, R. J. Auchus, R. Azziz, P. M. Sluss and H. Raff, "Position Statement: Utility, Limitations, and Pitfalls in Measuring Testosterone: An Endocrine Society Position Statement," The Journal of Clinical Endocrinology \& Metabolism, Vol. 92, No. 2, 2007, pp. 405-413. doi:10.1210/jc.2006-1864

[58] K. Bay, A. M. Andersson and N. E. Skakkebaek, "Estradiol Levels in Prepubertal Boys and Girls-Analytical Challenges," International Journal of Andrology, Vol. 27, No. 5, 2004, pp. 266-273. 
doi:10.1111/j.1365-2605.2004.00487.x

[59] M. M. Kushnir, A. L. Rockwood, W. L. Roberts, E. G. Pattison, A. M. Bunker, R. L. Fitzgerald and A. W. Meikle, "Performance Characteristics of a Novel Tandem Mass Spectrometry Assay for Serum Testosterone," Clinical Chemistry, Vol. 52, No. 1, 2006, pp. 120-128. doi:10.1373/clinchem.2005.052167

[60] R. Keen, "Osteoporosis: Strategies for Prevention and Management," Best Practice \& Research Clinical Rheumatology, Vol. 21, No. 1, 2007, pp. 109-122. doi:10.1016/j.berh.2006.10.004

[61] N. E. Lane, "An Update on Glucocorticoid-Induced Osteoporosis," Rheumatic Disease Clinics of North America, Vol. 27, No. 1, 2001, pp. 235-253. doi:10.1016/S0889-857X(05)70196-4

[62] R. T. Turner, "Skeletal Response to Alcohol," Alcoholism: Clinical and Experimental Research, Vol. 24, No. 11, 2000, pp. 1693-1701. doi:10.1111/j.1530-0277.2000.tb01971.x

[63] Z. Yuan, N. Dawson, G. S. Cooper, D. Einstadter, R. Cebul and A. A. Rimm, "Effects of Alcohol-Related Disease on Hip Fracture and Mortality: A Retrospective Cohort Study of Hospitalized Medicare Beneficiaries," American Journal of Public Health, Vol. 91, No. 7, 2001, pp. 1089-1093. doi:10.2105/AJPH.91.7.1089

[64] H. M. Perry 3rd and J. E. Morley, "Osteoporosis in Men: Are We Ready to Diagnose and Treat?" Current Rheumatology Reports, Vol. 3, No. 3, 2001, pp. 240-244. doi:10.1007/s11926-001-0024-3

[65] E. Orwoll, J. B. Blank, E. Barrett-Connor, J. Cauley, S. Cummings, K. Ensrud, C. Lewis, P. M. Cawthon, R. Marcus, L. M. Marshall, J. McGowan, K. Phipps, S. Sherman, M. L. Stefanick and K. Stone, "Design and Baseline Characteristics of the Osteoporotic Fractures in Men (MrOS) Study - A Large Observational Study of the Determinants of Fracture in Older Men," Contemporary Clinical Trials, Vol. 26, No. 5, 2005, pp. 569-585. doi:10.1016/i.cct.2005.05.006

[66] J. Placide and M. G. Martens, "Comparing Screening Methods for Osteoporosis," Current Women's Health Report, Vol. 3, No. 3, 2003, pp. 207-210.

[67] M. C. Hochberg, "Recommendations for Measurement of Bone Mineral Density and Identifying Persons to be Treated for Osteoporosis," Rheumatic Diseases Clinics of North America, Vol. 32, No. 4, 2006, pp. 681-689. doi:10.1016/j.rdc.2006.09.002

[68] D. C. Bauer, S. K. Ewing, J. A. Cauley, K. E. Ensrud, S. R. Cummings and E. S. Orwoll, "Quantitative Ultrasound Predicts Hip and Non-Spine Fracture in Men: The MrOS Study," Osteoporosis International, Vol. 18, No. 6, 2007, pp. 771-777. doi:10.1007/s00198-006-0317-5

[69] E. Orwoll, “Assessing Bone Density in Men," Journal of Bone and Mineral Research, Vol. 15, No. 10, 2000, pp. 1867-1870. doi:10.1359/jbmr.2000.15.10.1867

[70] M. Z. Allende-Vigo, "The Use of Biochemical Markers of Bone Turnover in Osteoporosis," Puerto Rico Health Sciences Journal, Vol. 26, No. 2, 2007, pp. 91-95.

[71] V. Rochira, A. Balestrieri, B. Madeo, L. Zirilli, A. R.
Granata and C. Carani, "Osteoporosis and Male Age-Related Hypogonadism: Role of Sex Steroids on Bone (Patho)Physiology," European Journal of Endocrinology, Vol. 169, No. 2, 2006, pp. 175-185. doi: $10.1530 /$ eje. 1.02088

[72] H. W. Daniell, "Osteoporosis Due to Androgen Deprivation Therapy in Men with Prostate Cancer," Urology, Vol. 58, No. 2, 2001, pp. 101-107. doi:10.1016/S0090-4295(01)01251-1

[73] R. M. Francis, "The Effects of Testosterone on Osteoporosis in Men," Clinical Endocrinology, Vol. 50, No. 4, 1999, pp. 411-414.

[74] H. K. Kamel, "Male Osteoporosis: New Trends in Diagnosis and Therapy," Drugs \& Aging, Vol. 22, No. 9, 2005, pp. 741-748. doi:10.2165/00002512-200522090-00003

[75] H. M. Behre, S. Kliesch, E. Leifke, T. M. Link and E. Nieschlag, "Long-Term Effect of Testosterone Therapy on Bone Mineral Density in Hypogonadal Men," The Journal of Clinical Endocrinology \& Metabolism, Vol. 82, No. 8, 1997, pp. 2386-2390. doi:10.1210/jc.82.8.2386

[76] P. J. Snyder, H. Peachey, P. Hannoush, J. A. Berlin, L. Loh, J. H. Holmes, A. Dlewati, J. Staley, J. Santanna, S. C. Kapoor, M. F. Attie, J. G. Haddad Jr. and B. L. Strom, "Effect of Testosterone Treatment on Bone Mineral Density in Men over 65 Years of Age," The Journal of Clinical Endocrinology \& Metabolism, Vol. 84, No. 6, 1999, pp. 1966-1972. doi:10.1210/jc.84.6.1966

[77] J. D. Scott, P. R. Wolfe, P. Anderson, G. R. Cohan and A. Scarsella, "Prospective Study of Topical Testosterone Gel (AndroGel) Versus Intramuscular Testosterone in Testosterone-Deficient HIV-Infected Men," HIV Clinical Trials, Vol. 8, No. 6, 2007, pp. 412-420. doi: $10.1310 /$ het $0806-412$

[78] A. Fabbri, E. Giannetta, A. Lenzi and A. M. Isidori, "Testosterone Treatment to Mimic Hormone Physiology in Androgen Replacement Therapy. A View on Testosterone Gel and Other Preparations Available," Expert Opinion on Biological Therapy, Vol. 7, No. 7, 2007, pp. 10931106. doi:10.1517/14712598.7.7.1093

[79] L. Katznelson, J. S. Finkelstein, D. A. Schoenfeld, D. I. Rosenthal, E. J. Anderson and A. Klibanski, "Increase in Bone Density and Lean Body Mass during Testosterone Administration in Men with Acquired Hypogonadism," The Journal of Clinical Endocrinology \& Metabolism, Vol. 81, No. 12, 1996, pp. 4358-4365. doi: $10.1210 /$ jc. 81.12 .4358

[80] C. Y. Guo, T. H. Jones and R. Eastell, "Treatment of Isolated Hypogonadotropic Hypogonadism Effect on Bone Mineral Density and Bone Turnover," The Journal of Clinical Endocrinology \& Metabolism, Vol. 82, No. 2, 1997, pp. 658-665. doi:10.1210/jc.82.2.658

[81] M. Horowitz, J. M. Wishart, P. D. O'Loughlin, H. A. Morris, A. G. Need and B. E. Nordin, "Osteoporosis and Klinefelter's Syndrome," Clinical Endocrinology, Vol. 36, No. 1, 1992, pp. 113-118. doi:10.1111/j.1365-2265.1992.tb02910.x

[82] J. P. van den Bergh, A. R. Hermus, A. I. Spruyt, C. G. Sweep, F. H. Corstens and A. G. Smals, "Bone Mineral Density and Quantitative Ultrasound Parameters in Pa- 
tients with Klinefelter's Syndrome after Long-Term Testosterone Substitution," Osteoporosis International, Vol. 12, No. 1, 2001, pp. 55-62. doi:10.1007/s001980170158

[83] C. Wang, G. Cunningham, A. Dobs, A. Iranmanesh, A. M. Matsumoto, P. J. Snyder, T. Weber, N. Berman, L. Hull and R. S. Swerdloff, "Long-Term Testosterone Gel (AndroGel) Treatment Maintains Beneficial Effects on Sexual Function and Mood, Lean and Fat Mass, and Bone Mineral Density in Hypogonadal Men," The Journal of Clinical Endocrinology \& Metabolism, Vol. 89, No. 5, 2004, pp. 2085-2098.doi:10.1210/jc.2003-032006

[84] D. von Muhlen, G. A. Laughlin, D. Kritz-Silverstein, J. Bergstrom and R. Bettencourt, "Effect of Dehydroepiandrosterone Supplementation on Bone Mineral Density, Bone Markers, and Body Composition in Older Adults: The DAWN Trial," Osteoporosis International, Vol. 19, No. 5, 2008, pp. 699-707. doi:10.1007/s00198-007-0520-z

[85] B. Lunenfeld, "Androgen Therapy in the Aging Male," World Journal of Urology, Vol. 21, No. 5, 2003, pp. 292305. doi:10.1007/s00345-003-0366-8

[86] A. M. Kenny and K. M. Prestwood, "Osteoporosis. Pathogenesis, Diagnosis, and Treatment in Older Adults," Rheumatic Disease Clinics of North America, Vol. 26, No. 3, 2000, pp. 569-591. doi:10.1016/S0889-857X(05)70157-5

[87] M. R. Smith, "Treatment-Related Osteoporosis in Men with Prostate Cancer," Clinical Cancer Research, Vol. 12, 2006, pp. 6315s-6319s. doi:10.1158/1078-0432.CCR-06-0846

[88] D. Kastelan, Z. Giljevic, I. Kraljevic and M. Korsic, "Selective Estrogen Receptor Modulators: A Possible New Treatment of Osteoporosis in Males," Medical Hypotheses, Vol. 67, No. 5, 2006, pp. 1052-1053. doi:10.1016/j.mehy.2006.04.040

[89] M. R. Smith, "The Role of Bisphosphonates in Men with Prostate Cancer Receiving Androgen Deprivation Therapy," Oncology, Vol. 18, No. 5, 2004, pp. 21-25.

[90] N. H. Bell and R. H. Johnson, "Bisphosphonates in the Treatment of Osteoporosis," Endocrine, Vol. 6, No. 2, 1997, pp. 203-206. doi:10.1007/BF02738966

[91] H. Fleisch, "Bisphosphonates: A New Class of Drugs in Diseases of Bone and Calcium Metabolism," Recent Results in Cancer Research, Vol. 116, 1989, pp. 1-28. doi:10.1007/978-3-642-83668-8 1

[92] C. MacLean, S. Newberry, M. Maglione, M. McMahon, V. Ranganath, M. Suttorp, W. Mojica, M. Timmer, A. Alexander, M. McNamara, S. B. Desai, A. Zhou, S. Chen, J. Carter, C. Tringale, D. Valentine, B. Johnsen and J. Grossman, "Systematic Review: Comparative Effectiveness of Treatments to Prevent Fractures in Men and Women with Low Bone Density or Osteoporosis," Annals of Internal Medicine, Vol. 148, No. 3, 2008, pp. 197-213. doi:10.7326/0003-4819-148-3-200802050-00198

[93] R. G. Russell, "Bisphosphonates: Mode of Action and Pharmacology," Pediatrics, Vol. 119, Suppl. 2, 2007, pp. S150-S162. doi:10.1542/peds.2006-2023H

[94] P. Valverde, "Pharmacotherapies to Manage Bone Loss-
Associated Diseases: A Quest for the Perfect Benefit-toRisk Ratio," Current Medicinal Chemistry, Vol. 15, No. 3, 2008, pp. 284-304. doi:10.2174/092986708783497274

[95] R. G. Russell, N. B. Watts, F. H. Ebetino and M. J. Rogers, "Mechanisms of Action of Bisphosphonates: Similarities and Differences and Their Potential Influence on Clinical Efficacy," Osteoporosis International, Vol. 19, No. 6, 2008, pp. 733-759. doi:10.1007/s00198-007-0540-8

[96] M. C. Hochberg and R. Rizzoli, "Long-Term Experience with Alendronate in the Treatment of Osteoporosis," Expert Opinion on Pharmacotherapy, Vol. 7, No. 9, 2006, pp. 1201-1210. doi:10.1517/14656566.7.9.1201

[97] S. P. Tuck and H. K. Datta, "Osteoporosis in the Aging Male: Treatment Options," Clinical Interventions in Aging, Vol. 2, No. 4, 2007, pp. 521-536.

[98] P. N. Sambrook, "How to Prevent Steroid Induced Osteoporosis," Annals of Rheumatic Diseases, Vol. 64, No. 2, 2005, pp. 176-178. doi:10.1136/ard.2003.018556

[99] M. Q. Lacy, A. Dispenzieri, M. A. Gertz, P. R. Greipp, K. L. Gollbach, S. R. Hayman, S. Kumar, J. A. Lust, S. V. Rajkumar, S. J. Russell, T. E. Witzig, S. R. Zeldenrust, D. Dingli, P. L. Bergsagel, R. Fonseca, C. B. Reeder, A. K. Stewart, V. Roy, R. J. Dalton, A. B. Carr, D. Kademani, E. E. Keller, C. F. Viozzi and R. A. Kyle, "Mayo Clinic Consensus Statement for the Use of Bisphosphonates in Multiple Myeloma," Mayo Clinic Proceedings, Vol. 81, No. 8, 2006, pp. 1047-1053. doi:10.4065/81.8.1047

[100] M. Pazianas, P. Miller, W. A. Blumentals, M. Bernal and P. Kothawala, "A Review of the Literature on Osteonecrosis of the Jaw in Patients with Osteoporosis Treated with Oral Bisphosphonates: Prevalence, Risk Factors, and Clinical Characteristics," Clinical Therapeutics, Vol. 29, No. 8, 2007, pp. 1548-1558. doi:10.1016/j.clinthera.2007.08.008

[101] M. H. Vieillard, J. M. Maes, G. Penel, T. Facon, L. Magro, J. Bonneterre and B. Cortet, "Thirteen Cases of Jaw Osteonecrosis in Patients on Bisphosphonate Therapy," Joint Bone Spine, Vol. 75, No. 1, 2008, pp. 34-40. doi:10.1016/j.jbspin.2007.05.003

[102] D. Agnusdei and R. Gentilella, "GH and IGF-I as Therapeutic Agents for Osteoporosis," Journal of Endocrinological Investigation, Vol. 28, Suppl. 8, 2005, pp. 3236.

[103] A. Toogood, "Safety and Efficacy of Growth Hormone Replacement Therapy in Adults," Expert Opinion on Drug Safety, Vol. 4, No. 6, 2005, pp. 1069-1082. doi:10.1517/14740338.4.6.1069

[104] E. Canalis, A. Giustina and J. P. Bilezikian, "Mechanisms of Anabolic Therapies for Osteoporosis," The New England Journal of Medicine, Vol. 357, 2007, pp. 905-916.

[105] K. Briot, F. Tremollieres, T. Thomas and C. Roux, "How Long Should Patients Take Medications for Postmenopausal Osteoporosis? Joint Bone Spine, Vol. 74, No. 1, 2007, pp. 24-31. doi:10.1016/j.jbspin.2006.05.011

[106] D. Bodenner, C. Redman and A. Riggs, "Teriparatide in the Management of Osteoporosis," Clinical Intervention in Aging, Vol. 2, No. 4, 2007, pp. 499-507. 